Council has met on ten occasions: four times in London, five times in Paris and once in Czechoslovakia. Among those who were to have attended the meeting at Cambridge were Prof. F. Joliot-Curic and Dr. Pierre Biquard (France), Academician Vassily Nikitin (U.S.S.R. Academy of Sciences), Madame I. Nikitina, Prof. I. Lebedev (president of the Higher Institutions and Scientific Workers' Union of the U.S.S.R.) and M. Oraevsky ; Prof. Tsien SanTsiang and Dr. Chi Tsin-Jen (Chinese Federation of Scientific Societies); Prof. L. Infeld and Prof. Z. Kuligowski (Polish Federation of Scientific Societies) ; Prof. I. Malek (Czechoslovakian Association of Scientific Workers), and representatives from India, Britain and the Dominions.

\section{Synthetic Fibres in Prospect and Retrospect}

THE second George Douglas Lecture to the Society of Dyers and Colourists, given by Dr. Rowland Hill in Manchester on March 7, was entitled "Synthetic Fibres in Prospect and Retrospect", and in it he gave some impressive figures to illustrate the magnitude of the effort required for the development of a synthetic fibre such as nylon or 'Terylene'. In the early phases an expenditure of 6 million dollars and the services of 230 chemists and engineers were deployed in research and development on nylon in the United States, and a further 21 million dollars were spent before commercial sales were made. To-day, the firm of Du Pont de Nemours has spent 45 million dollars in research alone and $196 \cdot 8$ million dollars on plant and facilities in the development of this single fibre. In Britain, Imperial Chemical Industries, Ltd., has recently completed a plant at Billingham for making five thousand tons a year of nylon polymer, and extensions are already under way to treble this capacity. This is probably the most varied and complex organic chemical plant of its kind in Great Britain, and the design effort alone has necessitated thirty-five design engineer man-years and more than two hundred draughtsman man-years, supported by necessary services. The final drawings totalled about three thousand, and the 29 -in. wide printing paper used for taking prints measured about twenty miles, or an area of six acres. Construction spread over three years required about fourteen hundred man-years with a peak of 750 men. The plant contains seven thousand valves, sixteen hundred major instruments and roughly a hundred and fifty miles of 'main-line' piping. 'The output of five thousand tons of polymer is fed to the spinning factory of British Nylon Spinners at Pontypool, emerging mainly as a continuous-filament nylon yarn, sufficient in length to encompass the earth thirty thousand times. The new plant for making 'Terylene' polyester fibre, upon which a start has been made at Wilton, is estimated to cost about $£ 8$ millions.

Handbook of Scientific Instruments and Apparatus

THE annual "Handbook of Scientific Instruments and Apparatus" prepared in connexion with the Physical Society's annual exhibitions and giving details of the exhibits is now well known. This year's Exhibition is being held in the Imperial College of Science and Technology, South Kensington, London, during the period April 3-8; as in previous years, admission is only by ticket. It will be formally opened by the president of the Physical Society, Prof. L. F. Bates, on April 3, at 10 a.m. On this occasion two discourses are to be given: (1) by Mr. B. N. Wallis (Vickers-Armstrongs, Ltd.) on "Engineer- ing Supersonic Aerodynamics", and (2) by Mr. E. R. Davies (Kodak, Itd.) on "The Physical Basis of Colour Photography". An additional lecture, just announced, will be given by Dr. K. Hickman, of Rochester, New York, an authority on high-vacua physics, who will speak on April 3 at 5.15 p.m. on "Torpidity of Liquid Surfaces". The prize distribution of the Craftsmanship and Draughtsmanship competition is to take place during the Exhibition (3 p.m. on Saturday, April 5). The Handbook for 1952 provides a comprehensive description of the many exhibits to be staged by 150 exhibitors. The exhibits cover a very wide field of physical instruments and materials used in their construction, while the exhibitors include not only industrial firms but also government research establishments and university laboratories. The Handbook is well printed on glossy paper and is profusely illustrated by numerous half-tone reproductions. The volume is essential to all workers interested in the progress and development of scientific instruments (pp. $x i+244+$ A.76. Physical Society, 1 Lowther Gardens, Prince Consort Road, London, S.W.7. 6s.; postage 1s. 3d.).

\section{Technical Information and Documents Unit}

Tнн Headquarters Technical Information Service of the Department of Scientific and Industrial Research has been merged with the Technical Information and Documents Unit of the Department and will in future be known by this latter name. The address of the Unit is Cunard Building, 15 Regent Street, London, S.W.1 (telephone, Whitehall 9788). There is a reading room on the third floor of the building, which is open during normal office hours on weekdays and Saturday mornings, and where all inquiries may be directed. The Unit. maintains a technical inquiry service and is the British centre for an international questions-andanswers scheme. The object of this scheme is to provide information about industrial techniques from the United States, Canada, France, Germany, Ireland, Sweden and the United Kingdom. It is hoped that the scheme will help to cut out unnecessary delay and expense in the development of production processes. Another function of the Unit is to receive unpublished reports from British and American sources and to issue summaries of them; many of these reports contain information which is not published in the normal way. In addition, the Unit holds the German industrial documents which were taken to Great Britain after the Second World War.

\section{Endeavour Prizes for Science Essays}

IN order to induce younger scientific workers to take an interest in the work of the British Association for the Advancement of Science and to raise the literary standard of scientific writing, Imperial Chemical Industries, Ltd., publishers of Endeavour, are offering a number of prizes for an essay, not exceeding four thousand words, on one of the following subjects: sulphur in medicine, science, and technology; oceanography; the origin of life; the influence of climate on technology; scientific research in polar regions; and gas discharge tubes. Competitors must be less than twenty-five years old and must send in their essays by June 2. The prizes will be 50,25 and 15 guineas, respectively, with two special awards of 5 guineas each to competitors less than eighteen, and in addition prize-winners will have expenses paid for attendance at the British Association meeting, which will be held this year in Belfast 